\title{
Cognitive Development of Children with Mental Disorders through Special Programs
}

\section{PhD Candidate Edo Sherifi}

\author{
University of Tirana \\ Social Sciences Faculty \\ Psychology and Pedagogy Departament \\ E-mail: edo_sherifi@yahoo.com Mobile :0672036631
}

\section{Doi:10.5901/ajis.2013.v2n2p429}

\section{Abstract}

Goal: Evidencing the effectiveness of Individual Education Program's application methods for the rehabilitation of children with limited intellectual capacities, autistic and Down syndrome for their integration in the community. Objective: Observing children capacities after program implementation (PEI-I, PEI-II, PEI-III), regarding development context: Self-service capacity, cognitive capacity, social ability, physique ability, and linguistic ability, and practical capacity, professional and emotional ability through vertical grills. Methodology: Instruments used for the study's data collection and processing are: Individual education program (PEI) of children with Down syndrome, intellectual incapacity, autistics, half structured interviews with parents, educators focus group, vertical grill observations with children, SONER test and SPSS program packet. Results: SONER test results show that mental medium age of children trained in 2002-2012 programs is up to 6 years old, untrained children for the same period is up to 6 months old. Results of trained children in the three cognitive ability programs for autistic, Down syndrome and the intellectual incapacitated children are different. Autistic children reached the full Likert scale up to 50\% -55\%, Down syndrome children 60\%-65\% and the intellectually incapacitated 75\%-80\%. In linguistic ability autistics were 55\%-60\%, Down syndrome $65 \%-75 \%$ and the intellectually incapacitated $80-90 \%$. In social ability autistics 60-70\%, Down syndrome $75-80 \%$ and the intellectually incapacitated $85 \%-90 \%$. Results of untrained children directly observed in the same period of 2002-2012 according to tests: Cognitive capacity of 2002, autistic children did not accomplish at all Likert scale measure up to $85-95 \%$ and in 2012, 75-85\%. Linguistic ability in 2002 85-95\% and in 2012, 70-85\%. In social ability in 2002 80-90\% and 2012,70$80 \%$. Down syndrome children in cognitive capacity in 2002, $85-90 \%$ and $2012,70-80 \%$. In linguistic ability in $2002,75-90 \%$ and 2012, 68-80\%. In social ability in 2002, 80-70\% and in 2012, 80-70\%. Children with mental weakness in 2002, 94-98\% and 2012, 85-80\%. In linguistic ability in 2002, 90-96\% and in 2012, 80-85\%. In social ability in 2002, 85-95\% and 2012, 75-88\%. Discussion. Study findings prove the hypothesis that individual educational programs application methods help the psychosocial, physical, linguistic and emotional rehabilitation of children with intellectual incapacities. The influence of such programs is different in all three diagnoses that represent children in this study. Due to the high levels of children's psycho-social parameters, the progress of the intellectually incapacitated children is higher in relation to autistic and Down syndrome children. Conclusions. Individual education programs (PEI) accelerate rehabilitation of Down syndrome, autistics and the intellectually incapacitated children to be integrated in the community.

Key words: Limited ability. Capacity. Social behaviour. Individual education program. Rehabilitation. Down syndrome. Typology of service. Intellectual incapacity. Autism.

\section{Introduction}

This study was conducted during the period 2002 - 2012 in Child Development Center, Tirana, and the target group of 30 mentally disabled children with biological age 7-18 years, diagnosed with: autism, intellectual disability and Down syndrome. Levels of children's psychosocial parameters are varied according to the respective diagnoses. Applying center staff consists of 6 educators and 10 specialists servicing to children.

The idea that these children are social beings like everyone else prompted the requirement of reference study center and multidisciplinary group to discuss the necessity of designing individual education program (PEI), for the rehabilitation of children and their integration into the community. This plan was based on modules developed by Mencap 123 Golden Lane London ORT and "Indicator of Swiss observation and teaching for children with mental and physical" (2002). 
From 2002 onwards the focus of the study was the development, enhancement and implementation of children's rehabilitation plans and individual education program (PEI), training them in areas of development according to the needs of each child and evaluation by a multidisciplinary team. Application of rehabilitation programs for each child was experimented in 2002-2005 in three development areas: in the area of training for self-service, in the sphere of physical training and training in the field of education. These plans and programs were enriched every year and observed by the applicant in each typology group and service for every child. This coincided with the first phase of research. At the end of this phase of testing was conducted with children for SONER test, which determined their mental age. The assessment of achievement observed that children have needs in other areas of development. Therefore, the second phase of this study included the years 2005-2008 two curricula were developed in the field of language training and practical training. Assessing the needs of children by the applicant in consultation with the multidisciplinary team also identified other areas of needs for children, training in social sphere, the sphere of vocational training and emotional aspect. These plans were applied and observed during the years 2008-2012. This period coincided with the third phase of the study.

In conducting the study was particularly important the focus group consisting of center staff, representatives of corresponding centers and field management structures. In focus group there were discussed 10 questions emphasizing on issues of study reference. Part of the study was the administration of a questionnaire enclosed with 160 variables, the target group of 30 children with mental disabilities, whose data were processed by SPSS statistical package. Semistructured interviews with parents of target-group research were a tool that provided compelling data to answer the research questions of the study.

Application of the plans and programs of educational workers and specialists, in collaboration with parents and children, speeds up the process of rehabilitation of children with disabilities and their impact on integration in real life, to enjoy legitimate rights.

An important part of the study are recommendations addressed to social public or private actors to contribute in creating equal opportunities for children with disabilities.

\section{Metodology.}

1. English standardized modules of child development.

2. Standardized Swiss Indicator for observation and teaching for children with mental- physical disabilities"

3. Observations with vertical grill.

4. Focus group with center staff employees who work directly with children.

5. Structured interviews with parents.

6. SONE-R and Griffiths tests, scales for measuring the level of autism.

\section{Results and Discussion}

\subsection{Direct observation results of six children: three in the experiment group and three in the control group.}

Child with Intellectual Disabilities treated with Individualized Education Programs (PEI $1+$ PEI $2+$ PEI3) developed in three areas: Cognitive ability. Linguistic ability. Social ability.

P.R. Child, age 7 and 10 months. Cognitive training had $80 \%$ of program sections fully accomplished. Language training had $90 \%$ of sections. Social Skills sections made $85 \%$ of the programs.

\subsection{Child with Intellectual Incapacity by untrained programs Individual education, achieved these results.}

Child U.A. Mental age 2.5. 3.4 years old. Achievements in years (2002.2012). Cognitive Training (94\% / 80\%) had no programs at all in 2002/2012. Lingual-training-lingual $(90 \% / 80)$ of the sections in test did not perform at all. In social skills $(80 \%$ and $75 \%)$ did not perform at all by Likert scale measuring. Minimum of child development is achieved in natural way.

3.3. Down syndrome child is part of experiment group in Individualized Education Programs (PEI I + PEI II + PEI III) development in three areas: Cognitive training. Language training. Social Skills. 
Down syndrome B.S. Mental age 6.8. Fully accomplished at the level of Likert scale in the following sections. Cognitive training $60 \%$. Linguistic training $65 \%$. Social training $75 \%$. B. M.Z. child, mental age $2.5,4.7$ years old, 6.5 and 6.8 years old. Practiced with Individualized Education Programs, during the period 2002-2012. Fully accomplished the level of Likert scale in following sections. Cognitive training $65 \%$. $75 \%$ linguistic training. Social training $80 \%$.

\subsection{Down syndrome child in a control group with Individualized Education Program resulted in:}

A.D. untrained child with Down syndrome with Individualized Education Program. 5.2 years old in mental age in 2002. Mental age in 2012. 2 years and 11 months. Achievement tests from 2002 to 2012. From initial testing in 2002 and the end of the period in 2012 shows that at least in Liker scale are the following results: Cognitive Training (90\% / 80\%). Linguistic Training (98\% / 80\%). Social Training (80\% / 70\%).

3.5. Autistic child group experimented with Individualized Education Programs (PEI $1+P E I 2+P E I 3)$ development in three areas: Cognitive training. Linguistic training. Social skills.

M.C. Child mental age 2.6, 4.7, 6.3 years old. Reaches full level in Likert scale in the following results. Cognitive training $55 \%$. Linguistic training $65 \%$. Social training. $70 \%$

\subsection{Untreated autistic child with individualistic Education programs (PEI-1) + (PEI-2) + (PEI 3).}

D.D. child mental age 2.6 years in 2002. In 2012. 3.4 years. Achievements testing the child in 2002/2012. Did not reach any accomplishment in columns Tested: Cognitive training (85\% / 75\%). Language training (85\% / 70\%). Social training $(80 \% / 70 \%)$.

4. Graphic presentation of results obtained by observing children directly, semi-structured interviews and focus group with parents and center staff, to share with six children: three (exercising with PEI Individualized Education programs $(1+2$ $+3)$ in The experiment group and three in the control group (The untrained with PEI $(1+2+3)$.

Graphic presentation of the achievements of children with intellectual disabilities through the application of Individualized Education Programs, PEl-1 (2002-2005), PEI-2 (2005-2008), PEI-3 (2008-2012).

\subsection{P.R. Child with intellectual disabilities. Cognitive training.}

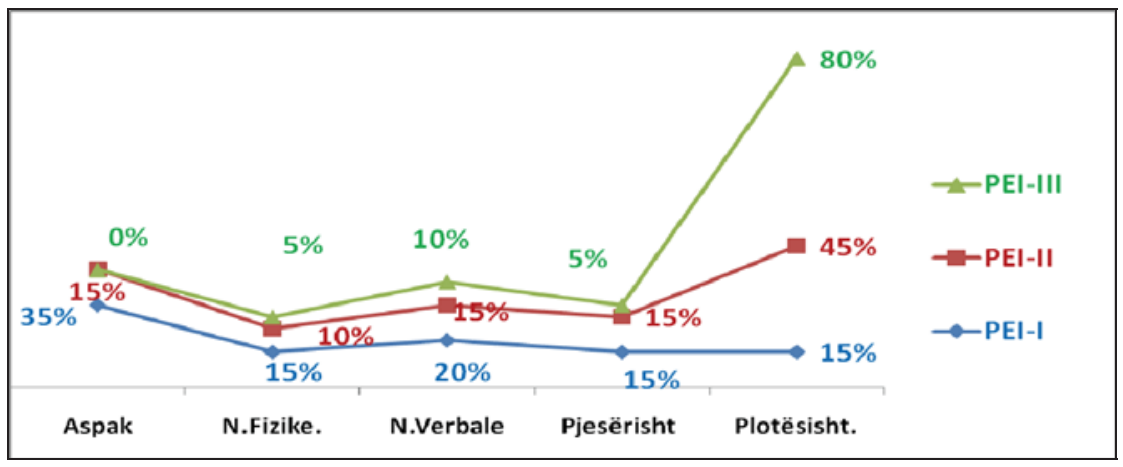

Graphic of section 4.4.1 shows that PR child with intellectual disabilities developed cognitively and progressively in proportion to the application of Individualized Education program $(P E I+2+3)$. Finding this section is entirely at: PEI 115\%. (PEI-2-45\%). (PEI 3-80\%) 
4.2. Communication training.

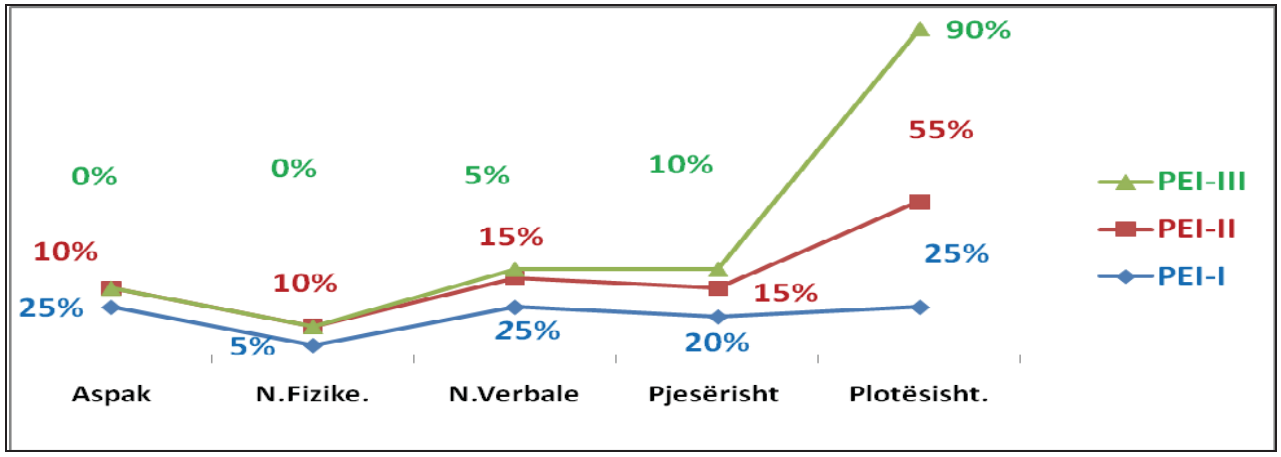

The findings of section 4.4.3. After applying the Individualized Education Program (PEl-1), enabling the child to grow $25 \%$. After application of (PEI-2), the child trained to communicate reached $55 \%$. At the end of the Individual Education Program PEI-3, enabling communication of child grew $90 \%$.

\subsection{Social Training.}

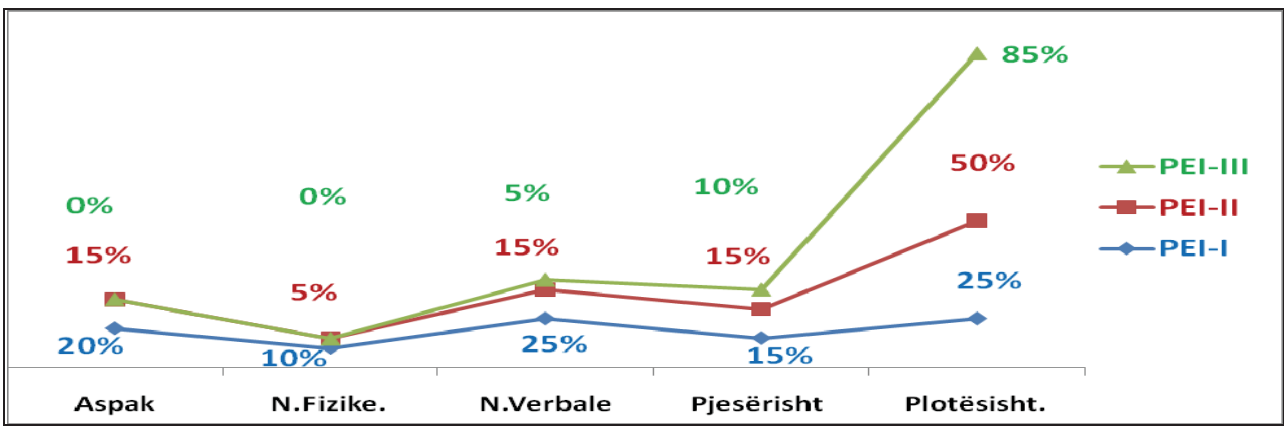

Findings of section 4.4 .3 are: social training has improved 25\% after application of PEI-1, 50\% after application of PEI-2, $85 \%$ after application of PEI-3.

\subsection{Graphic mental age of P.R.}

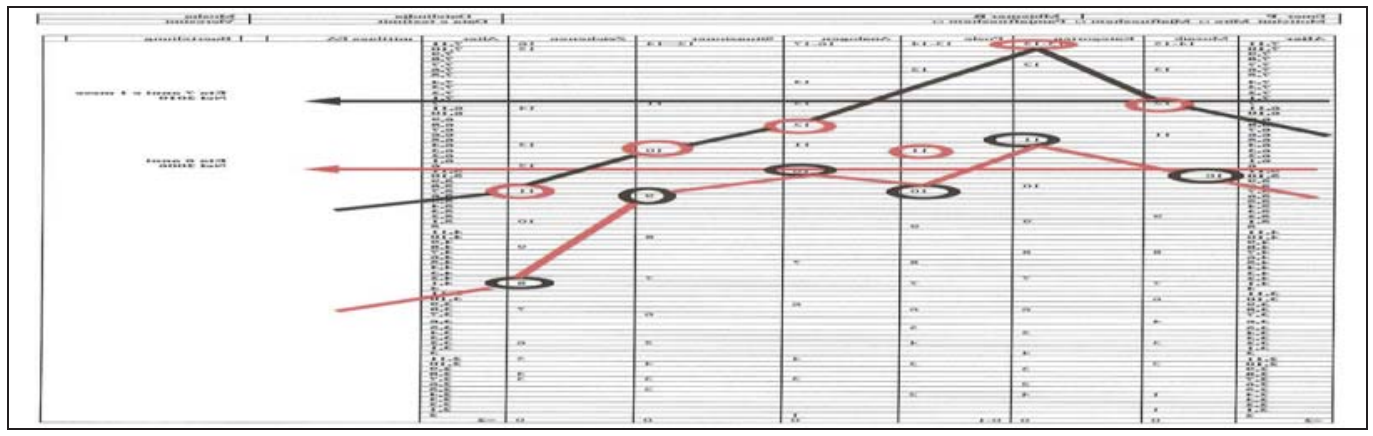

P.R.-2002 2.5 years old. 20064.7 years in 2011. 7.10 years 
4.5. Achievement of children with mental disability not exercised by Individual Education Program. (PEI). U.A. language training.

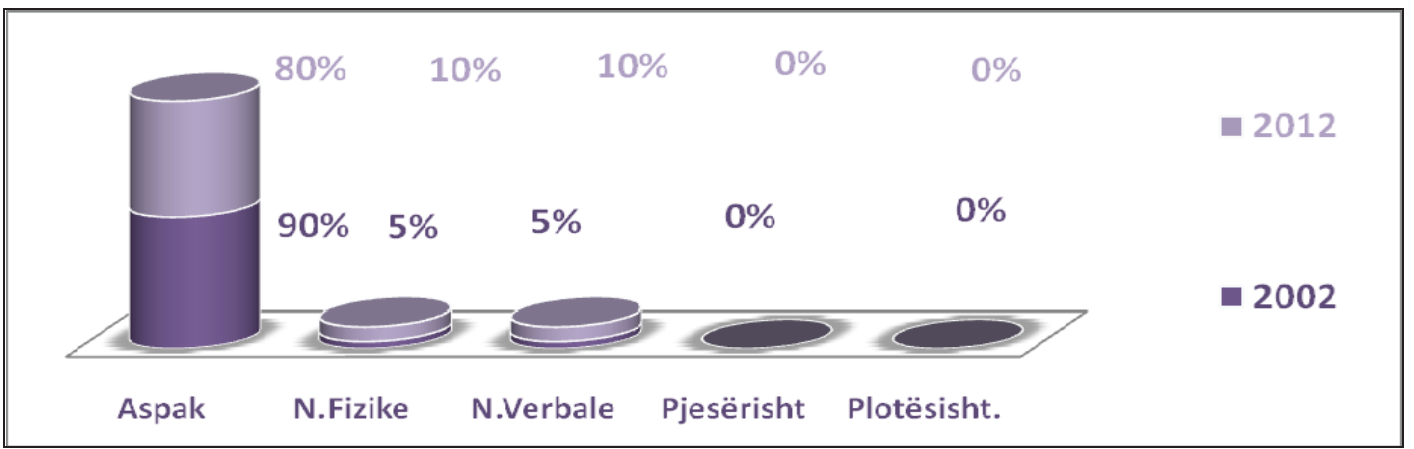

Graphic language of the child training control group shows that linguistic training in 2002 is $90 \%$ at least. In 2012 U.A. child's linguistic training of the untrained resulting $80 \%$ at least.

\subsection{U.A. Cognitive Training}

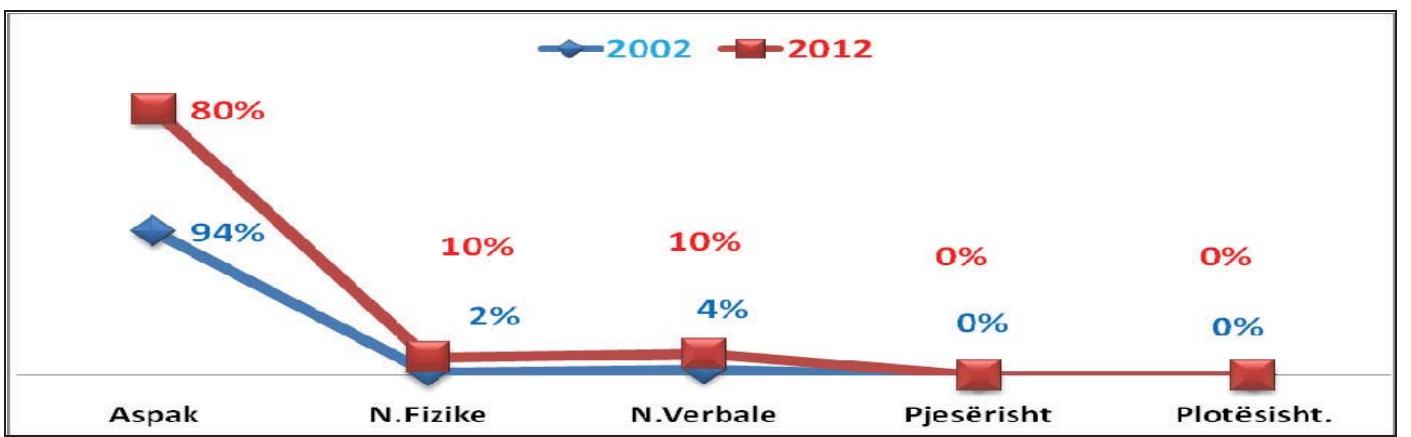

Graphic child's cognitive training U.A. control group shows that cognitive training in 2002 is at least $94 \%$. In 2012 AD child's cognitive training, the untrained programs resulting $80 \%$ at least.

4.7. Achievements of U.A child in the sphere of social training.

\begin{tabular}{|c|c|c|c|c|c|}
\hline & & $\% \quad 10 \%$ & $0 \%$ & $0 \%$ & \\
\hline & $85 \%$ & $10 \%$ & $0 \%$ & $0 \%$ & $\square 2012$ \\
\hline Aspak & N.Fizike & N.Verbale & Pjesërisht & Plotësisht. & \\
\hline
\end{tabular}


Graphic child's social training U.A. control group shows that in 2002 social training is at least $85 \%$. In 2012 U.A. child's social training, the untrained programs resulting $75 \%$ at least.

4.8. Graphics of U.A. child's mental age by SONE-R test.

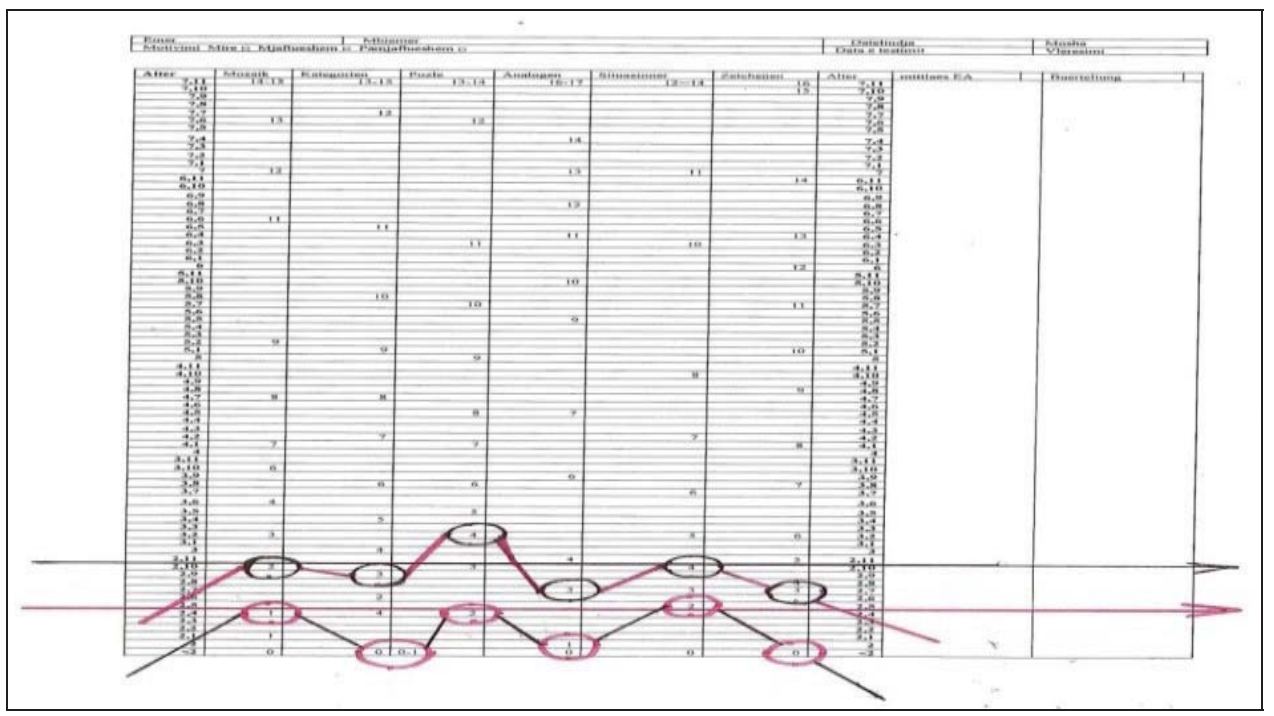

Mental age assessment of U.A. in 2002, 2.6 years; in 2011.3.4 years old

\section{PEI-I (2002-2005); PEI-II (2005-2008); PEI-III (2008-2012).}

4.9. Graphics of achievements for B.S. Down syndrome, Linguistic Training in the field.

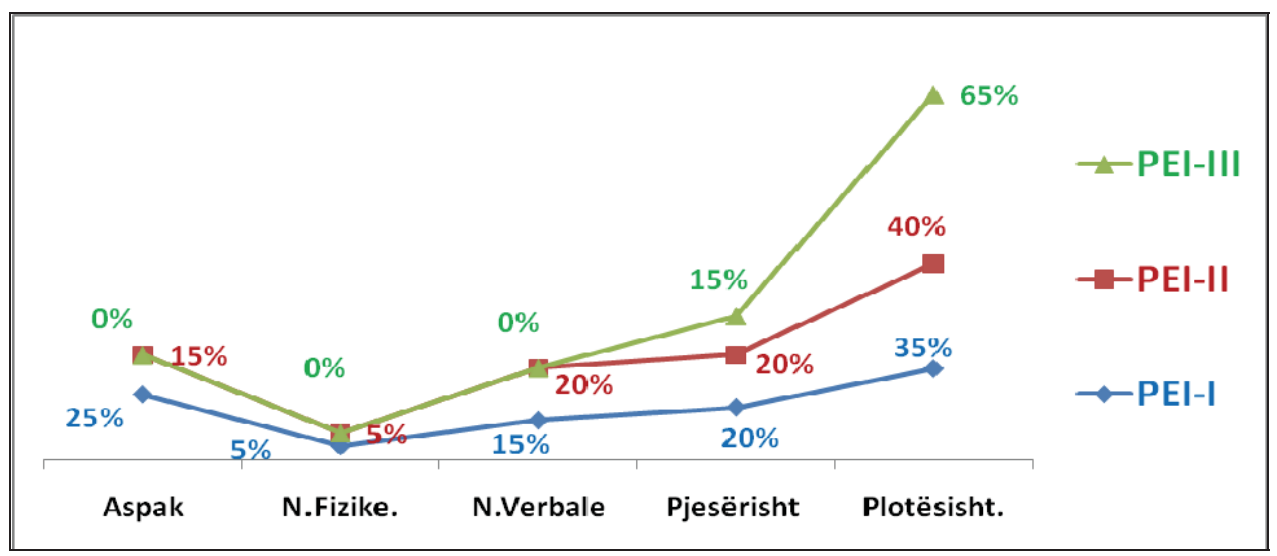

Findings of thread 4.4.6. After application of Individualized Education Program (PEI-1), enabling the child to grow 35\%. After application of (PEI-2), the child was trained to communicate fully at $40 \%$. At the end of the Individual Education Program PEI-3, enabling the child communication to increase $65 \%$. 
4.10. Graphic B.S. Cognitive Training

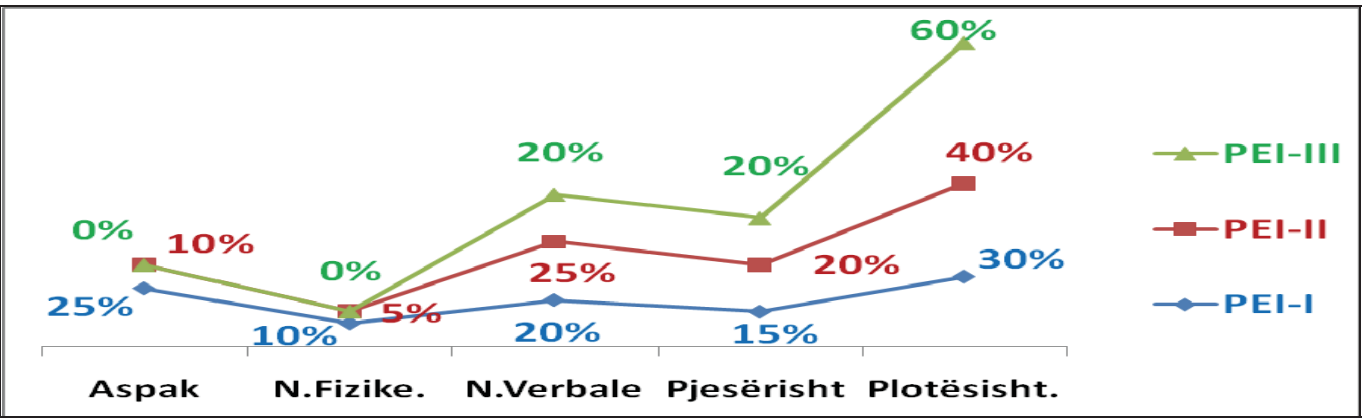

Graphic 4.4.18 shows that child B.S. place progressively in proportion to the application of Individualized Education program (PEI $1+2+3$ ) Findings in this section is entirely at: PEI 1-30\% /. (PEI 2-40\%). (PEI 3-60\%)

\subsection{Graphics of B.S. social training}

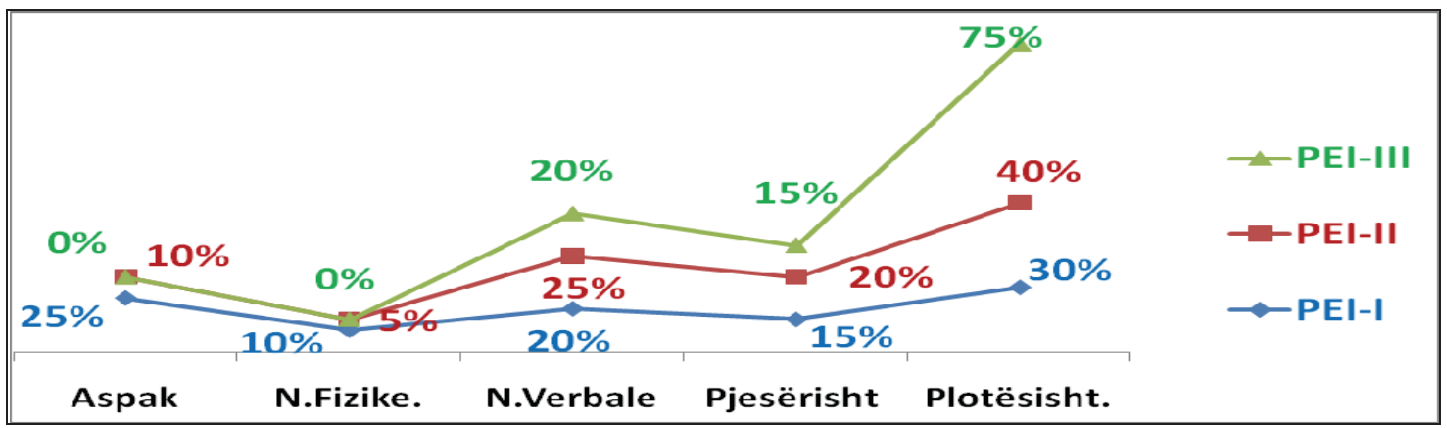

Finding section 4.4 .19 is: social training has improved $30 \%$ after application of PEI-1, $40 \%$ after application of PEI-2, and $75 \%$ after application of PEI-3.

4.12. Graphic mental age of B.S.

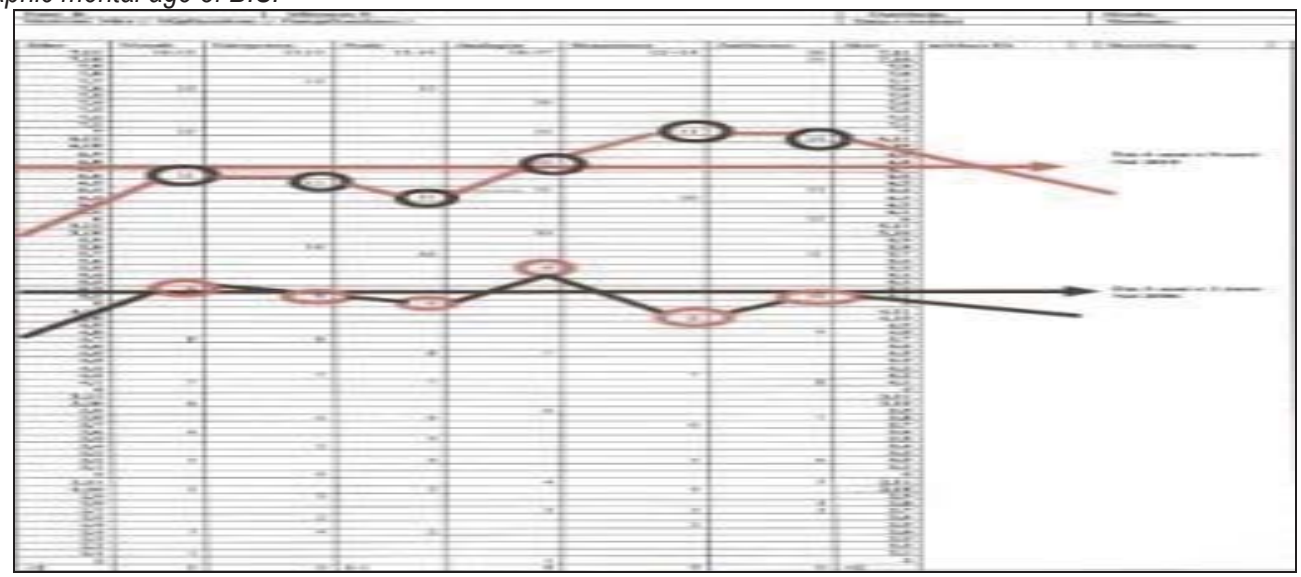

Child. BS .2002. 2.5 years old. 2006. 5.1 years old. 2011. 6.8 years old. 


\subsection{Graphic of K.K. Down syndrome child cognitive training}

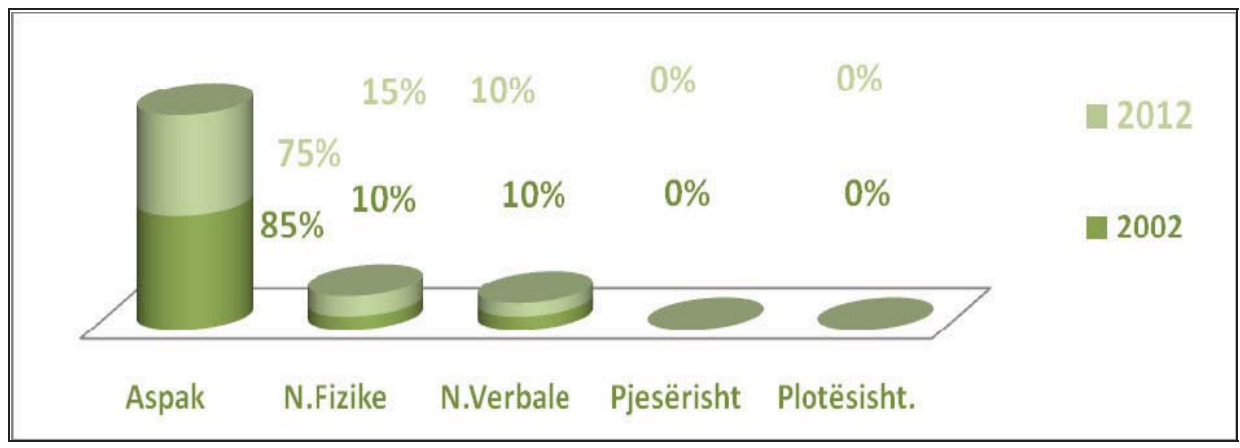

Graphic child's cognitive training in the control group shows that cognitive training in 2002 is at least $85 \%$. In 2012 the training of child cognitive results without exercise programs at least $75 \%$.

\subsection{Graphic of K.K. language training of the child with Down syndrome}

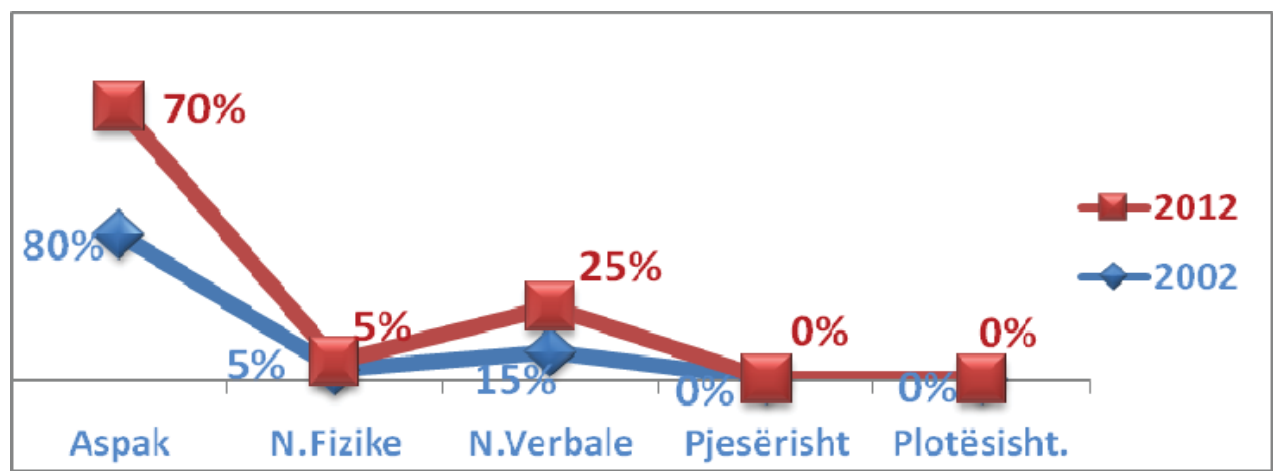

Graphic child's linguistic training in the control group shows that linguistic training in 2002 is $80 \%$ at least. In 2012 the training of child language K.K., the free exercise programs results at least $70 \%$ and $0 \%$ in partially and fully.

\subsection{Graphics of K.K. child with Down syndrome. Social Skills graphics}

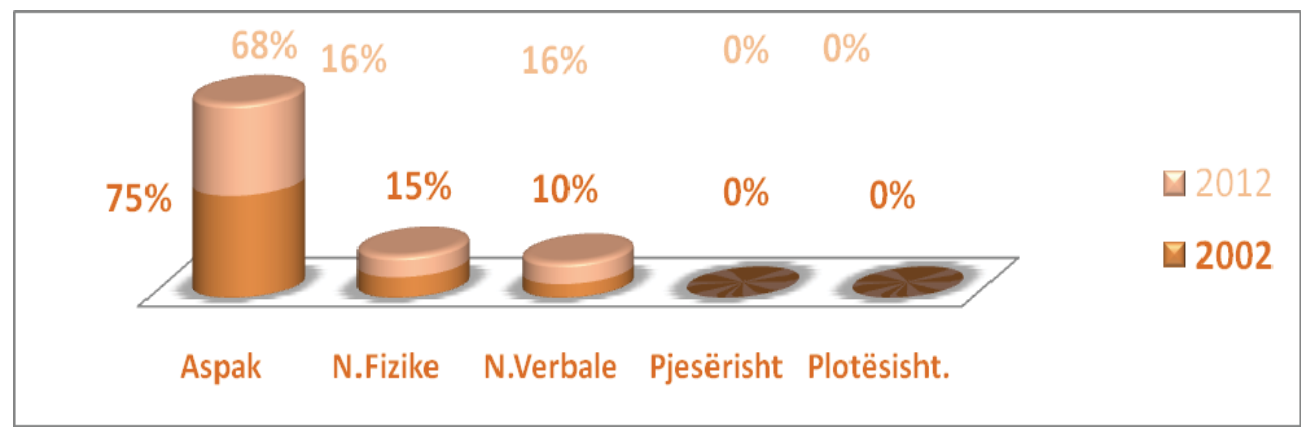

Graphic of K.K. child's social training in the control group shows that in 2002 social training is at least $75 \%$. In 2012 K.K. child social training exercised programs without resulting $68 \%$ at least, partially and fully. 


\subsection{Graphic of K.K. child's mental age.}

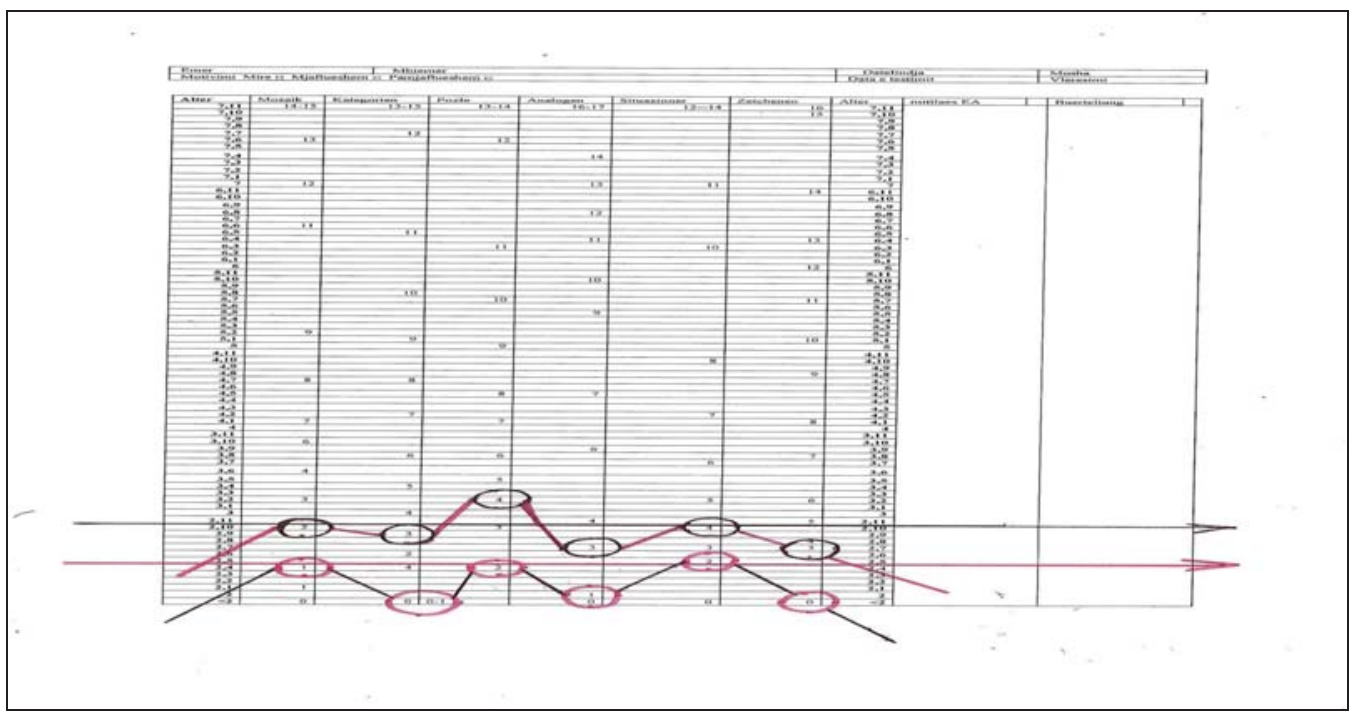

K.K. In 2002, 2.6 years old; in 2011 age 3.2. years old

TRAINED AUTISTIC CHILDREN

4:17. Graphic of M.C. child's cognitive training.

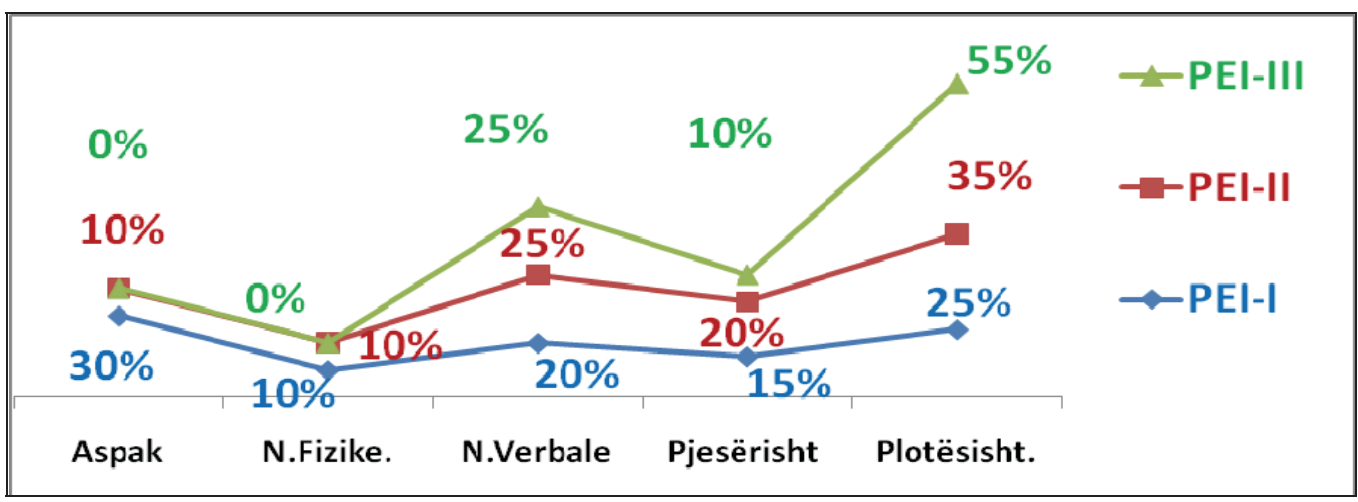

Graphic 4.4.29 shows the child M.C. place progressively in proportion to the application of Individualized Education program (PEI $1+2+3$ ). Finding this section is entirely at: PEI 1-25 \%. (PEI 2-35\%). (PEI 3-55\%)

\section{4:18. Graphic M.C in Linguistic training.}

Findings of section 4.4.30. After applying the Individualized Education Program (PEI-1), enabling the child to grow 30\%. After application of (PEI-2), the child was trained to communicate fully $45 \%$. At the end of the Individual Education Program PEI-3, enabling the child communication to increase $65 \%$. 
4:19. Graphic of M.C. child in Social training.

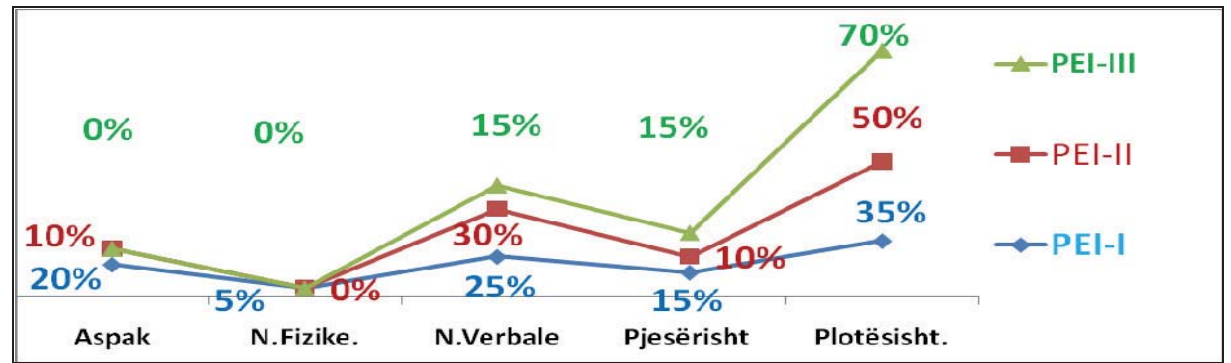

Findings of section 4.4 .31 are: social training has improved 35\% after application of PEI-1, 50\% after application of PEI-2, an $70 \%$ after application of PEI-3.

4.20. Graphic mental age of M.C.

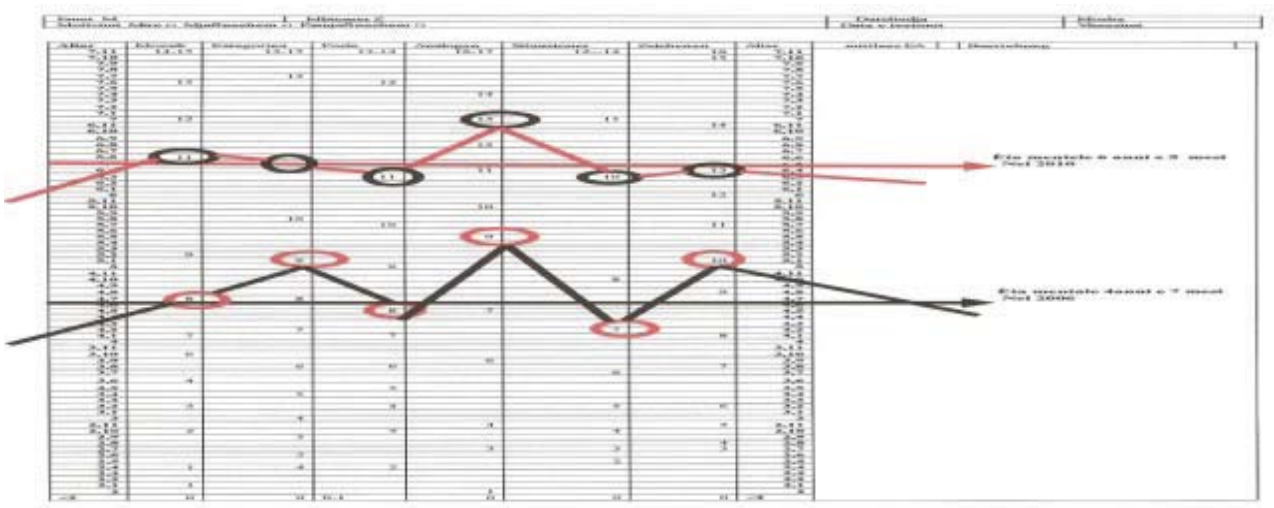

In $2002 \mathrm{MC}-2.5$ years. 4.7 years in 2006. In 2011. 6.3 years

Control Group.

Untrained Autistic Children with Individual Education Programs

4:21. Graphic of D.D. child's cognitive training.

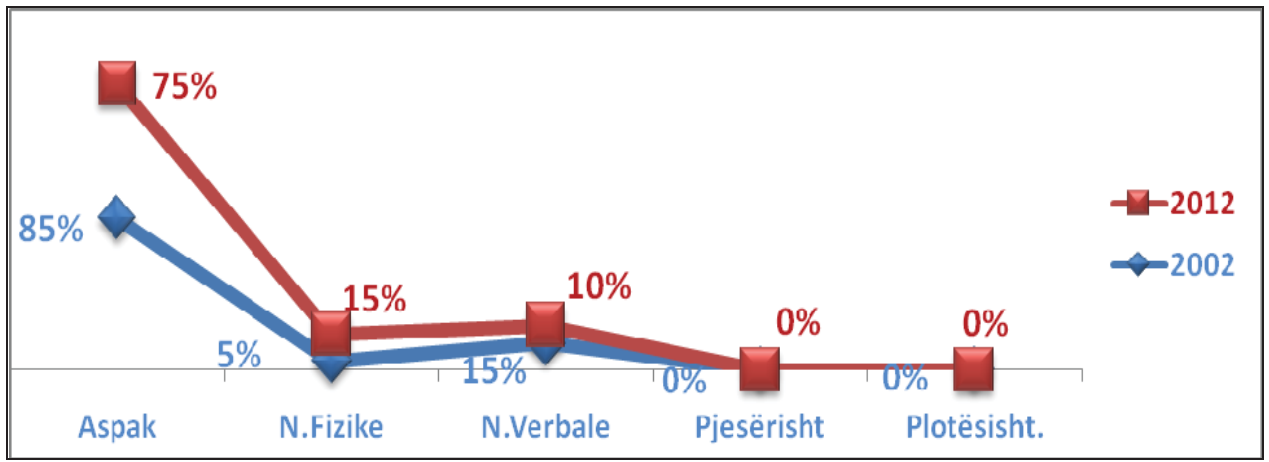


Graphic of language training to D.D. child in the control group shows that linguistic training in 2002 is at least $85 \%$. In 2012 D.D. child exercised language training programs without results at least $75 \%$ and $0 \%$ in partially and fully.

\subsection{Graphic of D.D. language training}

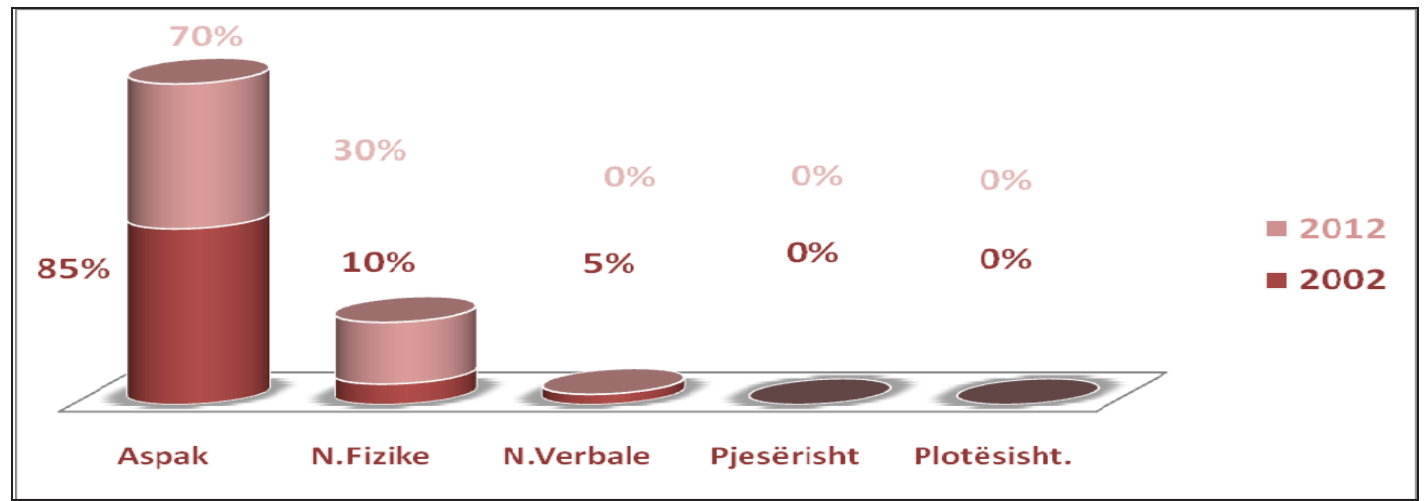

Graphic of the child Language training in the control group shows that in 2002 is $8.5 \%$ of language level in training. In 2012 D.D. child language training exercised programs without results at least $70 \%$ and $0 \%$ in partially and fully.

4.23. Graphical achievements of D.D. child in Social Skills.

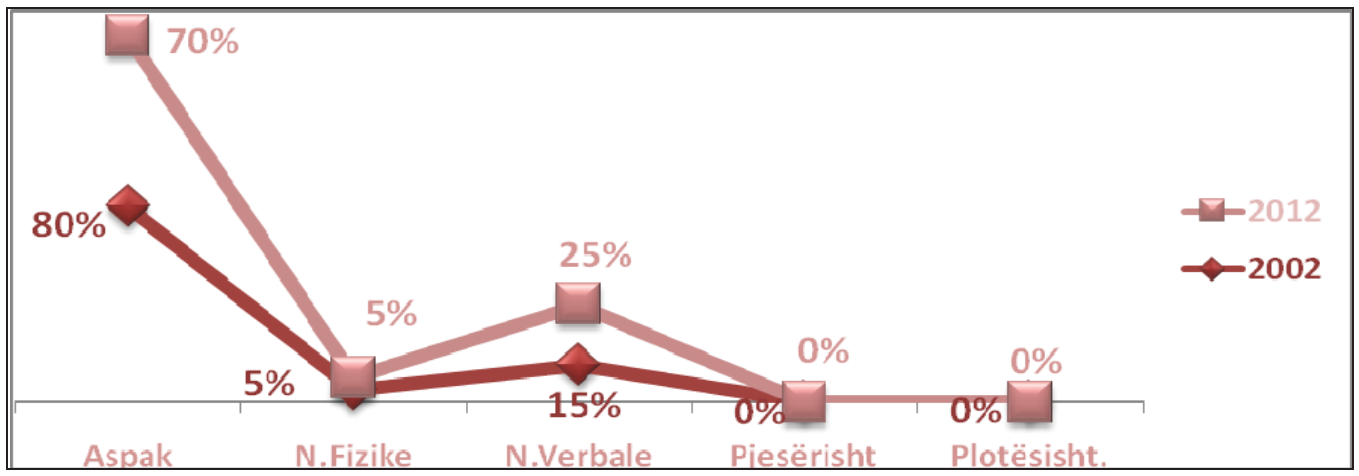

Graphic of D.D. child's social training in the control group shows that in 2002 social training is at least $80 \%$. In 2012 D.D. child social training exercised programs without resulting $70 \%$ at least, partially and fully. 
4:24. Graphic of D.D. child's mental age

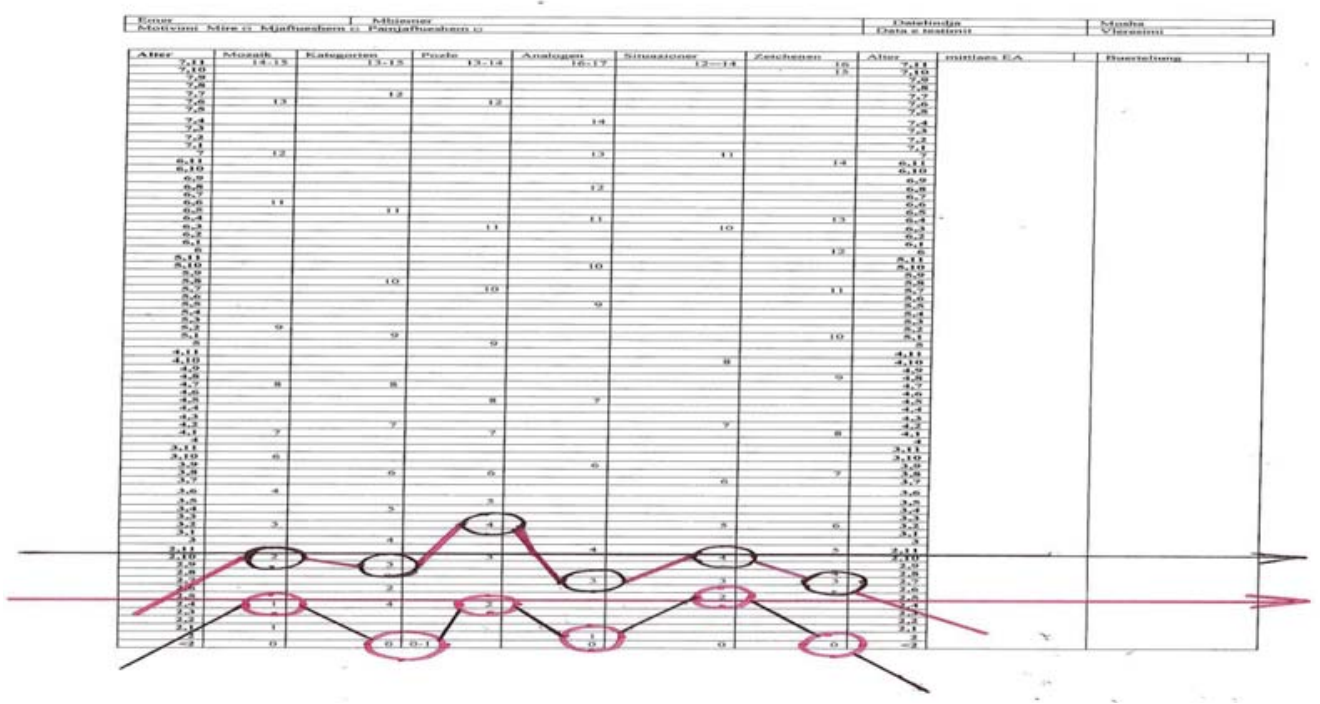

D.D. In 2002, 2.6 years; mental age in 2011 3.4. years old

\section{Conclusions}

Findings of the study gave a positive answer to the research hypothesis, the methods applied and the Individualized Education Programs (PEI) positively influenced the improvement of psychosocial parameters, the training and rehabilitation of Down syndrome children with intellectual disabilities and autism, creating skills and habits of professional skills to integrate into the community.

From direct observation of children is noted that in applying the methods for implementation of Individualized Education Programs (PEI) children assimilate various diagnoses of rehabilitation programs at various levels. Children with intellectual disabilities presented with the highest scores in the three areas of development: cognitive skills, communication skills and social skills.

In conclusion we can say that the individual education programs have different impacts on children of three diagnoses: autistic, Down syndrome and mental disorders. The level of progress of psychosocial parameters of these children is different to the three children of physiological damage diagnosis for children with various diagnoses are different to each of the children was observed.

At the end, the study positively resolved dilemmas that the application of scientific methods, educational programs helps in progress of psychological rehabilitation, social and language of children with disabilities and their integration accelerates in life outside the institution.

\section{References}

Allen, J., "Foucault and special educational needs: A box of tools for analyzing children's experiences of mainstreaming". Disability and Society 11 (2): 219- 233. (1996)

Alton, S., "Children with Down's syndrome and short term auditory memory".Down's Syndrome Association Journal 95 : 4-9. (2001)

Amundsen, R., "Disability, handicap and the environment". Journal of SocialPhilosophy 23 (1): 105-118. (1992)

Anastopoulos, A. D. and Farley., "S. E. A cognitive-behavioural training program for parents of children with attention-deficit/hyperactivity disorder". In: Kazdin, (2003)

Asperger, A., Autistischen psychopathen in kindesalter". Archiv fur Psychiatrie und Nervenkrankheiten 177: 76-136. (1944)

Baddeley, A. "Working memory and comprehension". In: Broadbent D., McGaug. J.Kosslyn M. etal. (Eds)Working Memory, 33-74. Oxford: Oxford Universit. Press. (1986) 
Baillargeon, R., Spelke, E. S. and Ëasserman, S., "Object permanence in 5-month old infants". Cognition 20: 191-208. (1985)

Baldini, S.,"Corpo rubato". Editore: Armando Tito Srl Roma. Fq.10. (1995)

Bargagna, S., "Sindrome Down". Le proposte per l'educazione e la riabilitazione. Editore: Edizioni del Cerro (collana Riabilitazione nei bambini), ottobre 2000. Pisa. Italia. Fq. 91,191. (2000).

Baron-Cohen, S., Ring, H. A., Bullmore, E. T. et al. "The amygdala theory of autism. Neuroscience and Biobehavioural Revieës" 24: 355-364. (2000) 
